\title{
Metamorphosis of the blue crab Callinectes sapidus: effects of humic acids and ammonium
}

\author{
Richard B. Forward, $\mathrm{Jr}^{1, *}$, Richard A. Tankersley ${ }^{2}$, Dimitri Blondel ${ }^{1}{ }$, Daniel Rittschof ${ }^{1}$ \\ 'Duke University, Nicholas School of the Environment, Marine Laboratory, 135 Duke Marine Lab Rd, Beaufort, \\ North Carolina 28516, USA \\ ${ }^{2}$ Department of Biological Sciences, University of Maryland Baltimore County, 1000 Hilltop Circle, Baltimore. \\ Maryland 21228-5398, USA
}

\begin{abstract}
Postlarvae (megalopae) of the blue crab Callinectes sapidus are transported from offshore/coastal areas into estuaries where they metamorphose (molt) to the first crab stage. Metamorphosis is accelerated by exposure to chemical cues in estuarine water. The present study tested the hypothesis that estuarine dissolved humic acids and ammonium serve as cues for accelerating metamorphosis. Estuarine humic acids are attractive as estuarine specific cues because they enter estuaries through freshwater inflow but precipitate as the salinity increases. Thus, estuarine humic acids are present in estuaries but occur in very low concentrations in coastal/offshore areas. Chemical cues that accelerate metamorphosis were present in river water entering an estuary. The time to metamorphosis decreased upon exposure to increasing concentrations of humic acids extracted from river water and to commercial humic acids. Thus, dissolved humic acids can serve as a cue for being in an estuary. High concentrations of ammonium chlonde ( $25 \mu \mathrm{M}$ and greater) delayed metamorphosis in estuarine water and reversed the accelerating effects of humic acids. Since high levels of ammonium usually occur in areas of low oxygen levels, this response may prevent megalopae from metamorphosing in these areas, which are less conducive to survival.
\end{abstract}

KEY WORDS: Blue crab Callnectes sapidus-Megalopae-Metamorphosis Humic acids Ammonium

\section{INTRODUCTION}

During the life cycle of the blue crab Callinectes sapidus, adults occur primarily in estuaries. Larvae are released near the entrance to estuaries and then transported offshore (Sandifer 1975, McConaugha et al. 1983) where they pass through 7 or 8 zoeal stages. They then molt to the postlarval or megalopa stage and are probably transported shoreward by wind-generated surface currents (Epifanio et al. 1984, Goodrich et al. 1989). Megalopae move up an estuary to the site of metamorphosis by means of selective tidal stream transport, in which they are in the water column on rising tides at night and absent at other times (Dittel \&

·E-mail: rforward@mail.duke.edu
Epifanio 1982, Brookings \& Epifanio 1985, Mense \& Wenner 1989, Little \& Epifanio 1991, De Vries et al. 1994, Olmi 1994).

Wolcatt \& De Vries (1994) hypothesized that metamorphosis was delayed in offshore water and accelerated by cues associated with estuaries. Their evidence was that the time to metamorphosis of megalopae collected offshore was reduced when they were exposed to low salinity water from an estuarine salt marsh. Subsequent studies identified some of the sources of cues that accelerate metamorphosis. Forward et al. (1994) demonstrated that the time to metamorphosis was reduced by exposure to low salinity water, estuarine water and the estuarine eelgrass Zostera marina. Brumbaugh \& McConaugha (1995) found metamorphosis was also accelerated by exposure to an alga (Ulva lactuca), which is abun- 
dant in estuaries. Finally, Forward et al. (1996) found that (1) exposure to 3 species of seagrasses and the salt marsh cord grass Spartina alterniflora accelerated metamorphosis, (2) chemical cues from plants mimicked exposure to the plants but structural cues had no effect and (3) cues from macroalgae varied in effectiveness with species. Collectively, these results support the suggestion that metamorphosis is accelerated by chemical cues from aquatic vegetation (Orth \& van Montfrans 1987, Lipcius et al. 1990, Olmi et al. 1990).

The present study was undertaken to test the hypothesis that 2 additional chemical substances (ammonium and humic acids) serve as cues for accelerating metamorphosis of megalopae of Callinectes sapidus. Brumbaugh's (1996) suggestion that ammonia/ammonium was a cue for blue crab metamorphosis is reasonable considering studies with other invertebrate larvae. Ammonia induces settlement behavior in oyster larvae (Coon et al. 1988, 1990, Bonar et al. 1990, Fitt \& Coon 1992) and metamorphosis of echinoderm (Gilmour 1991) and Japanese scallop (Kingzett et al. 1990) larvae, whereas ammonium causes metamorphosis of hydroid larvae (Berking 1988). Among crustaceans, ammonia accelerates molting in the shrimp Penaeus monodon (Chen \& Lin 1992). Alternatively, Zimmer-Faust \& Tamburri (1994) found that ammonium/ammonia did not induce settlement of oyster larvae.

Estuarine humic acids are a heterogeneous group of chemical species derived from terrestrial plant decomposition which enter estuaries through freshwater inflow (Stevenson \& Butler 1969). In addition, humic substances (Moran \& Hodson 1994) are produced by the degradation of Spartina alterniflora, which is abundant in many estuaries inhabited by blue crabs. Humic acids are hypothesized to act as the cue for metamorphosis because they are abundant in estuaries that recruit blue crabs (e.g. Fox 1981), and more importantly, they precipitate as the salinity increases (e.g. Sieburth \& Jensen 1968, Hair \& Bassett 1973). Thus, their concentration decreases from the head to the mouth of an estuary, and they are in very low concentrations in offshore areas. Hence, estuarine dissolved humic acids could serve as an unequivocal cue for location in an estuary.

The present study considered (1) whether metamorphosis-accelerating chemical cues enter an estuary in river water, (2) whether humic acids extracted from river water and commercial humic acids accelerate metamorphosis, and (3) the effect of ammonium and the combination of ammonium plus humic acids on metamorphosis. Humic acids were found to accelerate metamorphosis, which was inhibited by higher concentrations of ammonium.

\section{MATERIALS AND METHODS}

Megalopae of the blue crab Callinectes sapidus Rathbun were collected in plankton tows $10.67 \mathrm{~m}$ diameter net; $505 \mu \mathrm{m}$ mesh) from July to November, 1996 about $1 \mathrm{~km}$ inside the entrance to the Newport River Estuary (Beaufort, North Carolina, USA) on rising tides at night. Megalopae were quickly transferred into offshore water (see description below) and maintained in the laboratory overnight. The next day, they were sorted according to molt stage and only megalopae that were in intermolt (Aiken 1973, Anger 1983, Stevenson 1985) were used in experiments. Intermolt was indicated by body pigmentation and the absence of tissue withdrawal in the rostrum.

The general procedure was to test 54 megalopae for each treatment within each experiment. Megalopae were placed individually in compartments $(3.4 \times 3.4 \times$ $3 \mathrm{~cm}$ ) of a plastic box. Each box had 18 compartments, and each compartment was filled with about $20 \mathrm{ml}$ of the test solution. Using this procedure, each megalopa served as an independent replicate. Megalopae were maintained in an environmental chamber (Sherer model CEL-4) at temperatures and light:dark cycles similar to ambient conditions. The temperature was $25^{\circ} \mathrm{C}$ from July to October 17 and $20^{\circ} \mathrm{C}$ thereafter. The light:dark cycle was $14 \mathrm{~h}: 10 \mathrm{~h}$ from July to October 17. after which it was $12 \mathrm{~h}: 12 \mathrm{~h}$. The water in the compartments was changed daily and megalopae were fed brine shrimp nauplii (Artemia fransciscana Kellogg), which were recently hatched in offshore water. Plastic test boxes were washed with deionized water, rinsed twice and allowed to air dry overnight between use. Thus, a box was used every other day for the same treatment.

Each experiment tested the effect of different treatments on the time to metamorphosis (molting) of megalopae to the first crab stage. During a 24 h period, megalopae were monitored for molting at 6 or $8 \mathrm{~h}$ intervals. In the first 2 experiments $8 \mathrm{~h}$ was used, while $6 \mathrm{~h}$ was used thereafter to increase the resolution for determining the time of molting. Experiments continued until all megalopae had molted. Mortality was rare during experiments and for any treatment ranged from 0 to $5 \%$.

The time to metamorphosis was measured as the time interval between placement in the box and when molting was observed. The first observation time after midnight (06:00 or 08:00 h) was considered the beginning of the next day. Each experiment consisted of a number of different treatments. A cohort of megalopae was collected at the same time and haphazardly separated into boxes for the different treatments. The times to metamorphosis for the different treatments were then compared to determine the effect of treatment on 
metamorphosis. Since the previous study (Forward et al. 1996) indicated that molting rate varied significantly between cohorts, comparisons were not made between cohorts in different experiments.

There were 3 general types of test water 'Offshore Water' was collected about $15 \mathrm{~km}$ seaward of the Newport River Estuary inlet. This water was beyond the estuarine plume and from an area where megalopae were collected previously in the neuston (Forward \& Rittschof 1994). It was collected at the beginning of each experiment and stored in acid washed glass carboys at room temperature throughout the experiment. The salinity of Offshore Water was about 35 psu as measured with a refractometer (American Optical Co.), and any reductions in salinity were by the addition of distilled water. Offshore and distilled waters lack the metamorphosis-accelerating cues that are present in estuarine water (Forward et al. 1994, 1996).

'Estuarine Water' was obtained daily about $1 \mathrm{~km}$ inside the Newport River Estuary. On most days the salinity ranged from 33 to 35 psu. However, if on a particular day (1) the salinity of the Estuarine Water was $<33$ psu and (2) both Estuarine and Offshore Waters were being tested in an experiment, then the salinity of the Offshore Water was lowered by adding distilled water so that it matched Estuarine Water for that day. Thus, unless salinity was specifically being tested, the salinity of water for all treatments was the same on any day.

'River Water' was collected at the head of the Newport River Estuary and had a salinity of 0 psu. The salinity of this water was increased either by the addition of pure salts (Woods Hole recipe, Cavanaugh 1964) or by partially freezing Offshore Water and using the unfrozen brine as the source of salts. The former procedure had the advantage that known pure salts were used and the River Water was not diluted. Alternatively, the latter procedure retained the proportions of salts in Offshore Water. Since the brine had a salinity of about 125 psu, the volume of brine added to River Water to produce 35 psu reduced the volume of River Water in a test solution by about $38 \%$. This reduction should not have reduced the effect of River Water chemical cues on metamorphosis, since time to metamorphosis does not change upon a $50 \%$ dilution of Estuarine Water (Forward et al. 1996). All test waters were aerated before use and their $\mathrm{pH}$ was about 8.0 .

The 3 general sets of experiments tested the effects of humic acids, ammonium and the combination of humic acids and ammonium on the time to metamorphosis. It was assumed that Offshore Water was devoid of chemical cues that accelerated metamorphosis while these cues were present in Estuarine Water. Thus,
Estuarine and Offshore Waters alone were used as control treatments for the presence and absence of chemical cues, respectively. The effectiveness of humic acids and ammonium on metamorphosis was then tested by adding various concentrations of these substances to Offshore and Estuarine Waters.

Ammonium was added as ammonium chloride (Fisher Scientific Co.) to the test water. The 2 sources of humic acids were commercially available humic acids (Aldrich Chemical Co.) and those extracted from Newport River Water using the procedure of Fox (1981). For extraction, the River Water was first filtered through a Whatman GF/C glass fiber filter to remove particulate matter. The $\mathrm{pH}$ was then reduced to 2.0 by the addition of $1.0 \mathrm{M} \mathrm{H}_{2} \mathrm{SO}_{4}$ and the water filtered immediately through a GF/C filter to collect the precipitated humic acids. The filter was homogenized in $0.5 \mathrm{~N} \mathrm{NaOH}$ to dissolve the humic acids and the resultant centrifuged to remove the filter material. The supernatant containing concentrated humic acids was again acidified to a pH of 2.0 with $1.0 \mathrm{M} \mathrm{H}_{2} \mathrm{SO}_{4}$, and the precipitate collected by centrifugation. The precipitate was washed twice with $0.01 \mathrm{M} \mathrm{HCl}$, collected and air dried. Extraction yielded about $3 \mathrm{mg}$ of humic acids per liter of Newport River Water.

In every experiment where concentrations of a chemical were tested, the concentrations were made up each day from stock solutions. Ammonium chloride was dissolved in distilled water, while humic acids were dissolved in $0.1 \mathrm{~N} \mathrm{NaOH}$. To control for solvent effects, the same volumes of solvents were added to all treatments in each experiment. Since the design of the specific experiments varied, these are described in detail in the 'Results' section.

The effects of chemical cues on the time to metamorphosis of megalopae were determined using 1 - and 2-way ANOVA. For most experiments, time to metamorphosis values could not be transformed to meet the assumptions of normality and homogeneity of variances among groups for ANOVA. Therefore, the data were rank transformed prior to analysis using the procedures outlined by Conover \& Iman (1981). Since descriptive statistics of ranked values are often difficult to interpret, means $( \pm \mathrm{SE})$ for the original (non-transformed) data are plotted in the figures. If the 1-way ANOVA indicated significant treatment effects, a Dunnett's $t$-test for multiple comparisons (Dunnett 1964) was used to compare control means to all other treatment levels. If all treatment conditions were expected (a priori) to lengthen or shorten the time to metamorphosis relative to control conditions, a 1 -tailed statistical test was performed. For 2-factor experiments with significant main or interaction effects, differences among treatment combinations were determined using a Tukey multiple comparison test (Zar 1996). 


\section{RESULTS}

\section{River Water cues}

The initial experiments determined whether chemicals that accelerate metamorphosis were contained in Newport River Water. The salinity of the River Water was increased to 15,25 , and 35 psu by the addition of pure salts. Different salinities were tested because humic acids precipitate as the salinity increases. Thus, if only dissolved humic acids are the active chemical cue, then the effect of River Water on metamorphosis may decrease as the salinity increases. Humic acids that precipitated and flocculated over the $24 \mathrm{~h}$ exposure period to each day's test solution were not removed.

The time to metamorphosis was reduced in all salinities of River Water as compared to Offshore Water (Fig. 1). Two-way ANOVA indicated that time changed significantly with water type $(F=99.82 ; \mathrm{df}=$ $1,312 ; \mathrm{p}<0.001)$ but not salinity $(F=2.74 ; \mathrm{df}=2,312$; $\mathrm{p}>0.005)$ and there was no significant interaction effect $(F=1.95 ; \mathrm{df}=2,312 ; \mathrm{p}>0.05)$. The Tukey's multiple comparison test indicated that the times to metamorphosis in River Water at 25 and 35 psu were significantly $(\mathrm{p}<0.05)$ lower than those in Offshore Water at the same salinity.

A repeat of the experiment, in which the salinity of Newport River Water was increased by the addition of brine salts from Offshore Water, yielded similar results

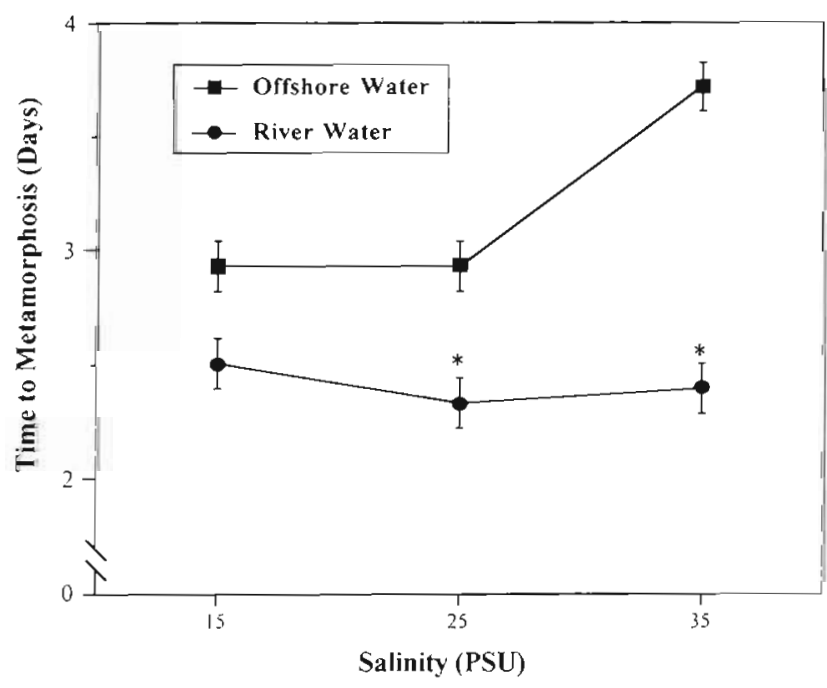

Fig. 1. Callinectes sapidus. Time to metamorphosis for megalopae in Offshore Water with salinity adjusted by distilled water and Newport River Water with salinity adjusted by the addition of pure salts. Means and standard errors are plotted. An asterisk indicates that time in River Water was significantly ( $p<0.05$; Tukey's multiple comparison test) shorter than the time at the same salinity in Offshore Water

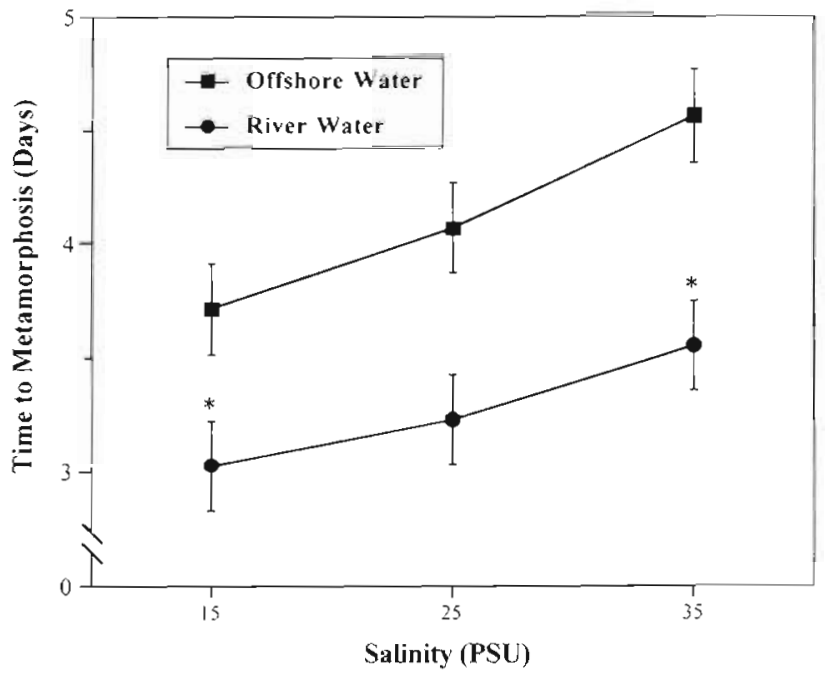

Fig. 2. Callinectes sapidus. Time to metamorphosis for megalopae in Offshore Water with salinity adjusted by distilled water and Newport River Water with salinity adjusted by the addition of brine from Offshore Water Means and standard errors are plotted. An asterisk indicates that the time in River Water was significantly ( $p<0.05$; Tukey's multiple comparison test) shorter than the time at that salinity in Offshore Water

(Fig. 2). As in the first experiment, time to metarnorphosis in River Water at all salinities was lower than in Offshore Water The 2-way ANOVA indicated there was a significant change in time to metamorphosis with water type $(F=27.69 ; \mathrm{df}=1,30 ; \mathrm{p}<0.001)$ and salinity $(F=9.32 ; \mathrm{df}=2,300 ; p<0.001)$ but there was no significant interaction between water type and salinity $(F=1.14 ; \mathrm{df}=2,300 ; \mathrm{p}>0.05)$. Tukey's multiple comparison test indicated that time was significantly $(\mathrm{p}<$ 0.05 ) shorter in 15 and 35 psu River Water as compared to Offshore Water at the same salinity.

Collectively, these results indicate that River Water contained chemical cues that decrease the time to metamorphosis. This result does not depend upon the type of salt used to alter the salinity. Finally, the effect of salinity alone between 15 and 35 psu on time to metamorphosis was weak.

\section{Humic acids}

Humic acids were extracted from Newport River water and tested at 3 concentrations in Offshore Water (Fig. 3). A 1-way ANOVA for Offshore Water and Offshore Water plus humic acids showed that there was a significant $(F=3.227$; $\mathrm{df}=3,206 ; \mathrm{p}<0.05)$ change in the time to metamorphosis with the addition of humic acids. The general trend was a reduc. tion in time with an increase in concentration. A Dun- 


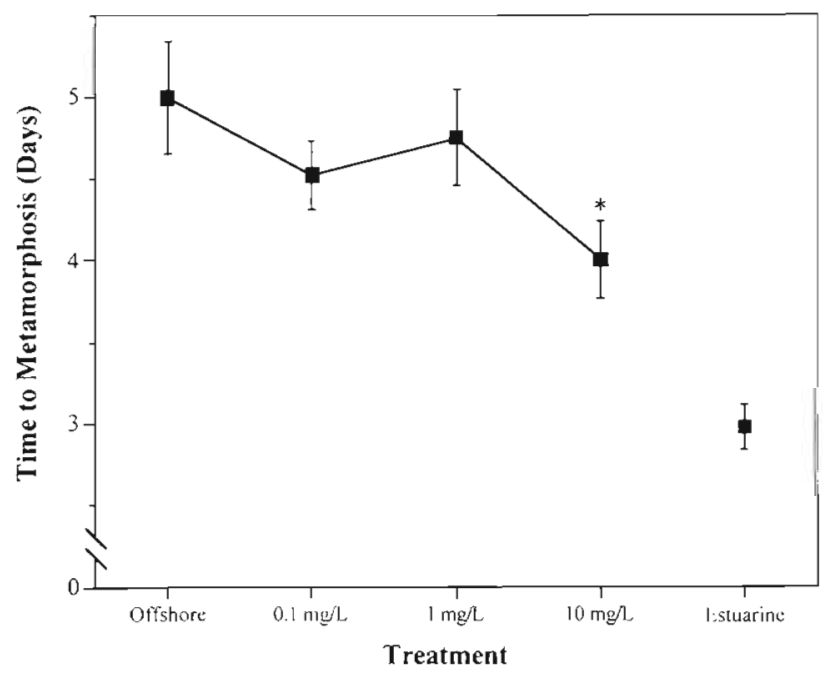

Fig. 3. Callinectes sapidus. Time to metamorphosis for megalopae in Offshore Water and Estuarine Water and in Offshore Water plus various concentrations of humic acids, which were extracted from the Newport River. Means and standard errors are plotted. The asterisk indicates that the mean time to metamorphosis upon exposure to that humic acid concentration was significantly $(\mathrm{p}<0.05$; Dunnett's multiple comparison test) shorter than that in Offshore Water

nett's multiple comparisons test (1-tailed) showed that exposure to $10 \mathrm{mg} \mathrm{l}^{-1}$ of humic acid was the only concentration that had a time that was significantly $(p<$ 0.05 ) shorter than that in Offshore Water. However, this time was still longer than that in the Estuarine Water control (Fig. 3).

A repeat of the experiment using commercial humic acids produced similar results (Fig. 4). The time to metamorphosis generally declined as humic acid concentration in Offshore Water increased. A 1-way ANOVA of Offshore Water and Offshore Water plus humic acids showed there was a significant $(F=2.27$; $\mathrm{df}=5,307 ; \mathrm{p}<0.05$ ) change in time to metamorphosis. A. Dunnett's multiple comparisons test (1-tailed) showed that the only humic acid concentration that significantly $(p<0.05)$ shortened the time to metamorphosis was $10 \mathrm{mg} \mathrm{l}^{-1}$. However, the time was longer than that in Estuarine Water (Fig. 4), as observed previously. Thus, these experiments indicate that exposure to humic acids shortens the time to metamorphosis and that the same results were obtained with extracted and commercial humic acids.

\section{Ammonium}

The times to metamorphosis upon exposure to various concentrations of ammonium chloride in Offshore Water were compared to those in Offshore and Estuar-

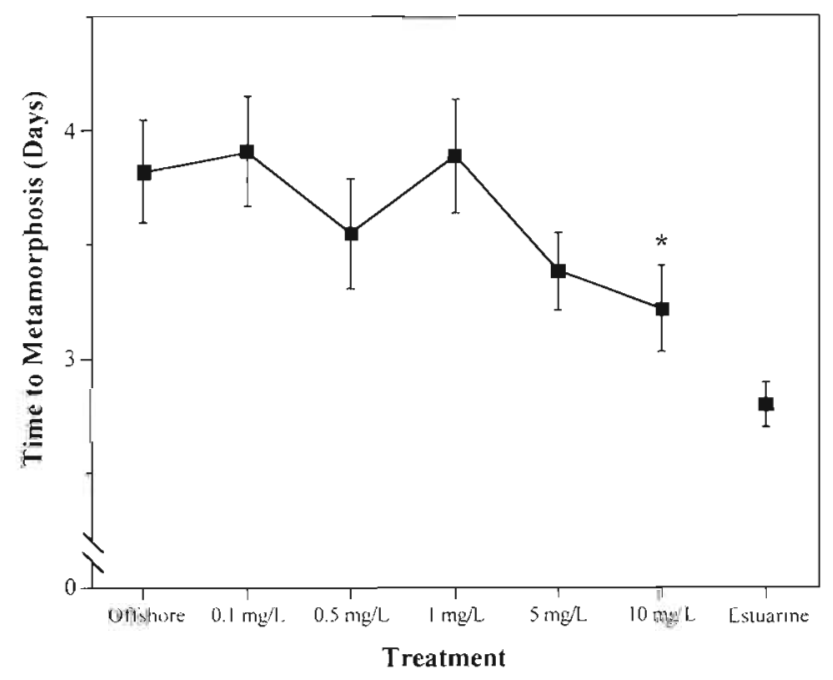

Fig. 4. Callinectes sapidus. Time to metamorphosis for megalopae in Offshore Water and Estuarine Water and in Offshore Water plus various concentrations of commercial humic acids. Means and standard errors are plotted. The asterisk indicates that the mean time to metamorphosis upon exposure to that humic acid concentration was significantly ( $p<0.05$; Dunnett's multiple comparison test) shorter than that in Offshore Water

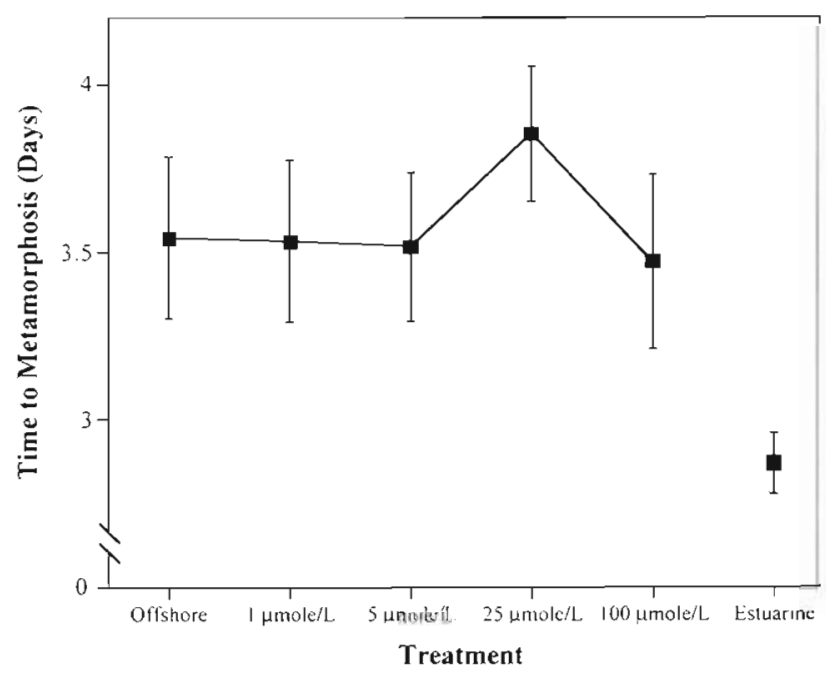

Fig. 5. Callinectes sapidus. Time to metamorphosis for megalopae in Offshore Water and Estuarine Water and in Offshore Water plus various concentrations ( $\mu \mathrm{M})$ of ammonium chloride. Means and standard errors are plotted

ine Waters (Fig. 5). A 1-way ANOVA on the Offshore Water and Offshore Water plus ammonium chloride did not show a significant change in time to metamorphosis $(F=1.34 ; \mathrm{df}=4,262 ; \mathrm{p}>0.05)$. All mean times were longer than that in Estuarine Water.

Different results were obtained when ammonium chloride was added to Estuarine Water (Fig. 6). The 


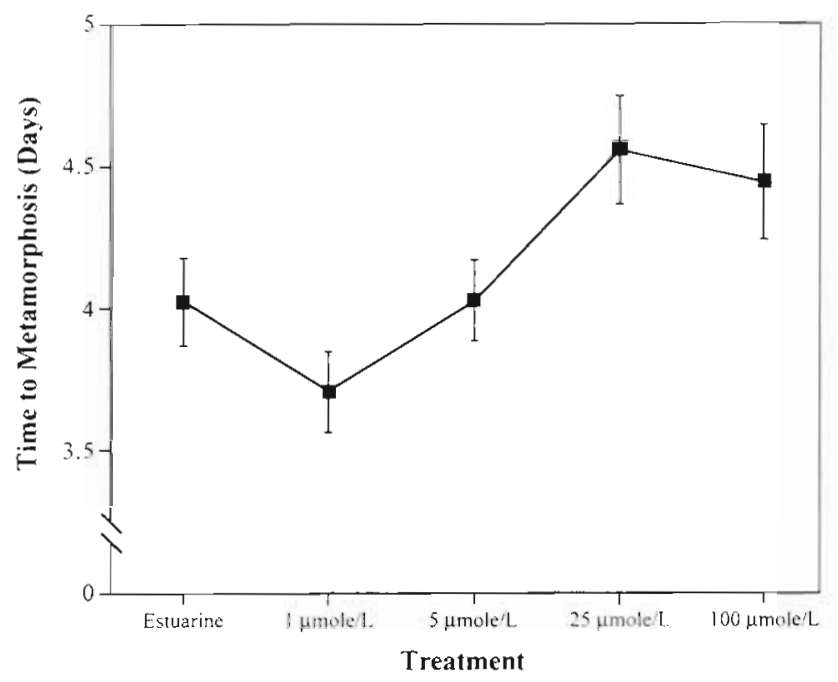

Fig. 6. Callinectes sapidus. Time to metamorphosis for megalopae in Estuarine Water alone and Estuarine Water plus various concentrations $(\mu \mathrm{M})$ of ammonium chloride. Means and standard errors are plotted

general trend was an increase in the time to metamorphosis as the concentration increased. One-way ANOVA showed a significant $(F=3.92 ; \mathrm{df}=4,260 ; \mathrm{p}<$ $0.005)$ effect of ammonium chloride concentration on time to metamorphosis. However, the Dunnett's multiple comparisons test (1-tailed) did not find any of the ammonium chloride treatments to be significantly different from the control in Estuarine Water.

\section{Humic acids plus ammonium}

The previous experiment demonstrated that the addition of humic acids at $10 \mathrm{mg}^{-1}$ to Offshore Water caused a significant decrease in the time to metamorphosis as compared to times in Offshore Water alone (Figs. 3 \& 4). Exposure to Estuarine Water also caused a shortening of the time (Figs. $3 \& 4$ ) due to the presence of humic acids and other possible chemical cues. However, the time to metamorphosis was unaltered when ammonium chloride was added to Offshore Water (Fig. 5), and when it was added to Estuarine Water, the time to metamorphosis increased with increasing concentration (Fig. 6). These results suggest that the effect of humic acids to accelerate metamorphosis may be reversed by the presence of ammonium chloride

The prediction that ammonium could reverse the effects of humic acids was tested by measuring the time to metamorphosis under the following conditions: (1) Estuarine Water alone, (2) Offshore Water alone, (3) Offshore Water plus $10 \mathrm{mg} \mathrm{l}^{-1}$ of commer-

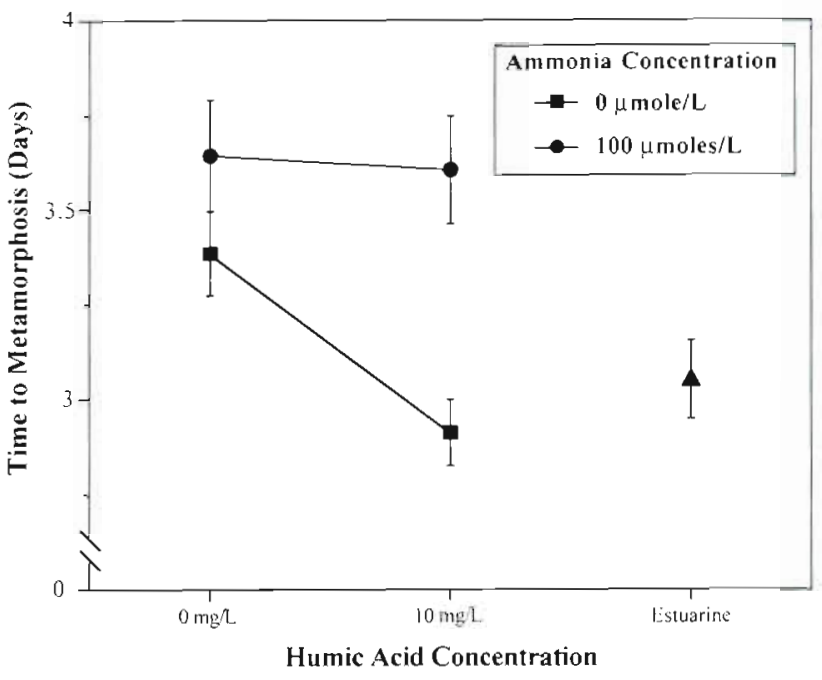

Fig. 7 Callinectes sapidus. Time to metamorphosis for megaIopae in Estuarine Water alone (Estuarine, $\Delta$ ) and Offshore Water with $0 \mu \mathrm{M}(\mathbf{D})$ and $100 \mu \mathrm{M}(\mathbf{0})$ of ammonium chloride. In addition, 0 and $10 \mathrm{mg} \mathrm{l}^{-1}$ of humic acids were added to the Offshore Water. Means and standard errors are plotted

cial humic acids, (4) Offshore Water plus $100 \mu \mathrm{M}$ ammonium chloride, (5) Offshore Water plus $100 \mu \mathrm{M}$ ammonium chloride and $10 \mathrm{mg} \mathrm{l}^{-1}$ commercial humic acids. These concentrations were chosen because they induced changes in the time to metamorphosis (Figs, 3, 4\&6). As expected, the time to metamorphosis in Estuarine Water was shorter than that in Offshore Water (Fig. 7). A 2-way ANOVA for the Offshore Water treatments indicated that there was a significant change in the time to metamorphosis in the presence of humic acids $(F=6.17$; $\mathrm{df}=1,206$; $\mathrm{p}<$ $0.05)$ and ammonium chloride $(F=13.27$; df $=1,206$; $\mathrm{p}<0.001)$ and that there was a significant $(F=6.92$; $\mathrm{df}=1,209 ; \mathrm{p}<0.01$ ) interaction effect. Individual treatment combinations were compared using the Tukey's multiple comparison test. The addition of humic acids to Offshore Water significantly ( $\mathrm{p}<$ 0.005 ) decreased the time to metamorphosis which verifies the results in Fig. 4. The addition of ammonium chloride to Offshore Water did not significantly change the time as compared to that in Offshore Water alone, which corroborates with the results in Fig. 5. Finally, upon the addition of humic acids and ammonium chloride, the time to metamorphosis was not significantly different from that for Offshore Water alone and Offshore Water plus ammonium chloride. However, the time in the presence of both humic acids and ammonium chloride was significantly $(p<0.001$ ) longer than that with only humic acids present. Thus, the prediction was supported: the molt accelerating effect of humic acids was reversed by the presence of ammonium chloride. 


\section{DISCUSSION}

After developing offshore (Sandifer 1975, McConaugha et al. 1983), blue crab megalopae enter estuaries (Dittel \& Epifanio 1982, Brookings \& Epifanio 1985, Mense \& Wenner 1989, Little \& Epifanio 1991, De Vries et al. 1994, Olmi 1994) where they metamorphose to the first crab stage. Metamorphosis is delayed in offshore water and accelerated by chemical cues in estuarine water (Forward et al. 1994, 1996, Wolcott \& De Vries 1994, Brumbaugh \& McConaugha 1995). The present study tested the hypothesis that estuarine humic acids and ammonium function as chemical cues for acceleration of metamorphosis.

Estuarine humic acids are primarily derived from the decomposition of terrestrial plants and enter streams and rivers by rain runoff (Schnitzer \& Kahn 1972). They are subsequently transported into estuaries by rivers, where they decrease in concentration rapidly though precipitation and dilution due to the increase in salinity as they move seaward (e.g. Sieburth \& Jensen 1968 , Hair \& Bassett 1973, Fox 1981). In the present study, Newport River Water contained chemical cues that accelerated metamorphosis. The chemical cues were equally active in River Water that had the salinity increased by the addition of pure salts (Fig. 1) or brine from Offshore Water (Fig. 2). Salts were not the source of the cues because megalopae in Offshore Water at the same salinity had slower times to metamorphosis.

Salinities at 15,25 , and 35 psu were tested to determine whether the effectiveness of humic acids varied with salinity. Since there was no statistical indication of an interaction between salinity and water type, the effect of water type was independent of salinity. If humic acids were the active chemical cue, the absence of an effect of salinity on humic acid activity could be due to the test procedure in that the test waters were added to the boxes immediately after the salinity was changed. The resulting precipitation and flocculation of humic acids occurred slowly over the next $24 \mathrm{~h}$. This mixture of dissolved, flocculated and precipitated humic acids would be similar to that in estuaries. However, since the precipitated and flocculated humic acids were not removed from the test solutions, the level of all types of humic acids was the same for all test solutions of River Water.

If either extracted or commercial humic acids were added to Offshore Water, the time to metamorphosis was reduced as the concentration increased (Figs. 3 \& 4) but was only significantly different from the control (Offshore Water alone) at the highest test concentration of $10 \mathrm{mg} \mathrm{l}^{-1}$. This concentration is slightly higher than the dissolved humic acids extracted from the Newport River (about $3 \mathrm{mg} \mathrm{l}^{-1}$ ) and maximum values reported for fresh and estuarine waters (e.g. $2.3 \mathrm{mg}$
$\mathrm{I}^{-1}$, Hair \& Bassett $1973 ; 3 \mathrm{mg} \mathrm{l^{-1 }}$, Noureddin \& Courtot 1989; $4.3 \mathrm{mg} \mathrm{l}^{-1}$, El-Sayed et al. 1993). Since similar results were obtained with humic acids extracted from River Water and commercially prepared humic acids, the latter can be used to measure the effects of natural dissolved estuarine humic acids.

These results support the hypothesis that humic acids, which are characteristic of estuaries, act as cues for metamorphosis. Humic acids are a heterogeneous class of refractory molecules. Terrestrially derived humics, such as those in rivers, are very different from humic acids derived from oceanic sources (Stuermer \& Harvey 1974). The latter have different elemental composition, organic sources, and chromophores than terrestrial humic acids (e.g. Kalle 1966, Sieburth \& Jensen 1968, Nissenbaum \& Kaplan 1972, De Souza Sierra et al. 1994).

In most experiments, humic acids were less potent accelerators of metamorphosis than estuarine or riverine water. The technique for extracting humic acids separated humics from other similar molecules, such as fulvic acids and compounds like geosmim and earthy substances, which are also characteristic of fresh water and estuaries (Sorensen 1986, Tosi \& Sola 1993). In most chemosensory systems, mixtures of chemicals are more potent that fractionated components (Carr \& Derby $1986 a, b)$. The results support the hypothesis that mixtures are involved in acceleration of metamorphosis because humic acids did not accelerate metamorphosis as much as Estuarine Water (Figs. 3 \& 4). Additional chemical cues in Estuarine Water are probably derived from estuarine aquatic vegetation (Forward et al. 1996).

At the $\mathrm{pH}$ of the test waters (about 8.0 ), $96 \%$ of the added ammonium existed as ammonium ion and $4 \%$ as ammonia (Bower \& Bidwell 1978). When added to Offshore Water, ammonium chloride had no effect on the time to metamorphosis at concentrations up to $100 \mu \mathrm{M}$ (Fig. 5). Alternatively, in Estuarine Water an increase in concentration of ammonium chloride caused an increase in the time to metamorphosis (Fig. 6), which indicates a general inhibition of the estuarine cues that accelerate metamorphosis. Finally, the metamorphosis-accelerating effect of humic acid was reversed by the presence of ammonium chloride (Fig. 7).

These results conflict with previous studies of other invertebrate larvae which showed that ammonia or ammonium induce settlement behavior (e.g. Coon et al. 1990, Fitt \& Coon 1992) and metamorphosis (Berking 1988, Kingzett et al. 1990, Gilmour 1991). However, Zimmer-Faust \& Tamburri (1994) found that ammonium did not affect settlement of oyster larvae. Levels of ammonia species in estuaries vary with time of day, state of the tide and location. In the water col- 
umn in the Newport River Estuary, Litaker et al. (1993) found that concentrations were low during the day and had maximum values at night in the range of 3 to $5 \mu \mathrm{M}$. Considering Fig. 6, it is unlikely that these levels would affect metamorphosis of blue crab megalopae in an estuary.

Blue crab megalopae settle preferentially in seagrass beds (Orth \& van Montfrans 1987. Olmi et al. 1990). Measurements of ammonium in seagrass beds in the Newport River Estuary indicated that levels increased from sediment surface values of about $50 \mu \mathrm{M}$ to much higher levels deep in the substrate (Kenworthy et al. 1982). These sediment values are sufficiently high to inhibit metamorphosis, which suggests metamorphosis would proceed faster if megalopae avoid the sediment in seagrass beds.

In addition, blue crab juveniles are found in oyster shells, which suggest megalopae may settle on oyster reefs (D. B. Eggleston, L. L. Etherington \& W. E. Elis unpubl.). Extensive measurement (Fitt \& Coon 1992) around oyster reefs in Georgia (USA) indicated that water over the reefs had high levels of ammonium at low tide (maximum $=20 \mu \mathrm{M}$ ) and low values at high tide. Higher values consistently in excess of $100 \mu \mathrm{M}$ were observed on the surface of oyster shells and in the crevices between oysters. These high values suggest metamorphosis would be inhibited in oyster reef areas. A possible functional explanation for inhibition of blue crab metamorphosis by ammonium chloride is that ammonium levels are inversely related to oxygen levels (Fitt \& Coon 1992). Thus, high ammonium levels may signal low oxygen level, which could be detrimental to megalopae.

Considering studies to date of blue crab megalopae, metamorphosis is affected by a variety of cues (Table 1). It is delayed in offshore water (Forward et al. 1994, 1996, Wolcott \& De Vries 1994, Brumbaugh \& McConaugha 1995) and accelerated by chemical cues in estuaries (Forward et al. 1994, 1996) and river water which include lower salinity and humic acids. Ammonium chloride is the first cue found to inhibit the accelerating effects of estuarine chemical cues. Chemical cues from estuarine aquatic vegetation, such as seagrasses, salt marsh cord grass (Forward et al., 1994, 1996) and some algae (Brumbaugh \& McConaugha 1995, Forward et al. 1996), also accelerate metamor-

Table 1. Summary of effects of various cues on the time to metamorphosis of blue crab Callinectes sapidus, megalopae

\begin{tabular}{|c|c|c|}
\hline Cue & Effect on metamorphosis & Source \\
\hline \multicolumn{3}{|l|}{ Water type } \\
\hline Offshore & Delay & $\begin{array}{l}\text { Wolcott \& De Vries (1994), Forward et al. (1994), } \\
\text { (1996), Brumbaugh \& McConaugha (1995), this study }\end{array}$ \\
\hline Estuarine & Accelerate & Forward et al. (1994), (1996), this study \\
\hline River & Accelerate & This study \\
\hline \multicolumn{3}{|l|}{ Estuarine chemical cues } \\
\hline Humic acids & Accelerate & This study \\
\hline Ammonium chloride & Delay & This study \\
\hline Salinity decrease & Accelerate & Forward et al. (1994), Wolcott \& De Vries (1994) \\
\hline \multicolumn{3}{|l|}{ Aquatic vegetation } \\
\hline \multicolumn{3}{|l|}{ Seagrasses } \\
\hline Zostera marina & Accelerate & Forward et al. (1996) \\
\hline Halodule wrightii & Accelerate & Forward et al. (1996) \\
\hline Ruppia maritima & Accelerate & Forward et al. (1.996) \\
\hline \multicolumn{3}{|l|}{ Macroalgae } \\
\hline Ulva lactuca & Accelerate & Brumbaugh \& McConaugha (1995) \\
\hline Ulva rotundata & Accelerate & Forward et al. (1996) \\
\hline Bryopsis plumosa & Accelerate & Forward et al. (1996) \\
\hline Enteromorphasp. & No effect & Forward et al. (1996) \\
\hline Hypnea musciformis & Accelerate & Forward et al (1996) \\
\hline Gracilaria sp. & No effect & Brumbaugh \& McConaugha (1995) \\
\hline Scyphosiphon lomentaria & No effect & Forward et al. (1996) \\
\hline Sargassum natans & No effect & Forward et al. (1996) \\
\hline \multicolumn{3}{|l|}{ Saltmarsh cord grass } \\
\hline Spartina alterniflora & Accelerate & Forward et al. (1996) \\
\hline \multicolumn{3}{|l|}{ Substrate } \\
\hline Clean oyster shells & No effect & Forward et al. (1996) \\
\hline Plastic rods, ribbon & No effect & Forward et al. (1996) \\
\hline Glass rods & No effect & Forward et al. (1996) \\
\hline
\end{tabular}


phosis. Alternatively, structure (e.g. clean mollusc shells, plastic, glass) has no demonstrated effect on metamorphosis (Forward et al. 1996). Since blue crabs have no home estuary (Forward et al. 1996), metamorphosis is accelerated by general cues within estuaries. Estuarine humic acids and lower salinity would indicate location within an estuary, while cues from estuarine aquatic vegetation could induce metamorphosis in areas of specific vegetation.

Acknowledgements. This material was based on research supported by the National Science Foundation (OCE9216629) and the North Carolina Sea Grant (\#NA56FE0551).

\section{LITERATURE CITED}

Aiken DE (1973) Proecdysis, setal development, and molt prediction in the American lobster (Homarus americanus). J Fish Res Bd Can 30:1337-1344

Anger K (1983) Moult cycle and metamorphosis in Hyas araneus larvae (Decapoda, Majidae), reared in the laboratory. Helgoländer Meeresunters 36:285-302

Berking S (1988) Ammonia, tetramethylammonium, barium and amiloride induce metamorhphosis in the marine hydroid Hydractinia. Roux's Arch Dev Biol 197:1-9

Bonar DB, Coon SL, Walsh M, Weiner RM, Fitt W (1990) Control of oyster settlement and metamorphosis by endogenous and exogenous cues. Bull Mar Sci 46:484-498

Bower CE, Bidwell JP (1978) Ionization of ammonia in seawater: effects of temperature, $\mathrm{pH}$ and salinity. J Fish Res Bd Can 35:1012-1016

Brookings KG, Epifanio CE (1985) Abundance of brachyuran larvae in a small coastal inlet over 6 consecutive tidal cycles. Estuaries 8:60-67

Brumbaugh RD (1996) Recruitiment of blue crab Callinectes sapidus postlarvae to the back-barrier lagoons of Virginia's Eastern Shore. PhD dissertation, Old Dominion University, Norfolk, VA

Brumbaugh RD, McConaugha JR (1995) Time to metamorphosis of blue crab Callinectes sapidus megalopae: effects of benthic macroalgae. Mar Ecol Prog Ser 129:113-118

Carr WES, Derby CD (1986a) Chemically stimulated feeding behavior in marine animals: the importance of chemical mixtures and the involvement of mixture interactions. J Chem Ecol 12:987-1099

Carr WES, Derby CD (1986b) Behavioral chemoattractants for the shrimp, Palaemonetes pugio: identification of active components in food extracts and evidence of synergistic mixture interactions. Chem Sen 11:49-64

Cavanaugh GM (1964) Formulae and methods $V$. of the Marine Biological Laboratory Chemical room. Marine Biological Laboratory, Woods Hole, MA

Chen JC, Lin CY (1992) Effects of ammonia on growth and molting of Penaeus monodon juveniles. Comp Biochem Physiol 101C:449-452

Conover WJ, Iman RL (1981) Rank transformations as a bridge between parametric and nonparametric statistics. Am Stat 35:124-129

Coon SL, Walch M, Fitt WK, Bonar DB, Weiner RM (1988) Induction of settlement behavior in oyster larvae by ammonia. Am Zool 28:70A

Coon SL, Walch W, Fitt WK, Weiner RM, Bonar DB (1990) Ammonia induces settlement behavior in oysters larvae. Biol Bull (Woods Hole) 179:297-303
De Souza Sierra MM, Donard OFX, Lamotte M, Belin C, Ewald M (1994) Fluorescence spectroscopy of coastal and marine waters. Mar Chem 47:127-144

DeVries MC, Tankersley RA, Forward RB Jr, Kirby-Smith WW, Luettich RA (1994) Abundances of crab megalopae are associated with estuarine tidal hydrologic variables. Mar Biol 118:403-413

Dittel AI, Epifanio CE (1982) Seasonal abundance and vertical distribution of crab larvae in Delaware Bay, USA. Estuaries $5: 197-202$

Dunnett CW (1964) New tables for multiple comparisons with a control. Biometrics 20:282-491

El-Sayed MA, Aboul Naga WM, Halim Y (1993) Dissolved humic substances in a coastal lagoon of the Nile Delta: distribution, inputs and behaviour. Estuar Coast Shelf Sci 36: $464-475$

Epifanio CE, Valenti CC, Pembroke AE (1984) Dispersal and recruitment of blue crab larvae in the Delaware Bay, USA. Estuar Coast Shelf Sci 18:1-12

Fitt WK, Coon SL (1992) Evidence for ammonia as a natural cue for recruitment of oyster larvae to oyster beds in a Georgia salt marsh. Biol Bull (Woods Hole) 182:401-408

Forward RB Jr, De Vries MC, Rittschof D, Frankel DAZ, Bischoff JP, Fisher CM, Welch JM (1996) Effects of environmental cues on metamorphosis of the blue crab Callinectes sapidus. Mar Ecol Prog Ser 131:165-177

Forward RB Jr, Frankel DAZ, Rittschof D (1994) Molting of megalopae from the blue crab Callinectes sapidus: effects of offshore and estuarine cues. Mar Ecol Prog Ser 113 $55-59$

Forward RB Jr, Rittschof D (1994) Photoresponses of crab megalopae in offshore and estuarine waters: implications for transport. J Exp Mar Biol Ecol 182:183-192

Fox LE (1981) The geochemistry of humic acid and iron during estuarine mixing. PhD dissertation, University of Delaware, Lewes

Gilmour THJ (1991) Induction of metamorphosis of echinoderm larvae. Am Zool 31:105A

Goodrich DM, van Montfrans J, Orth RJ (1989) Blue crab megalopal influx to the Chesapeake Bay: evidence for a wind-driven mechanism. Estuar Coast Shelf Sci 29: $247-260$

Hair ME, Bassett CR (1973) Dissolved and particulate humic acids in an east coast estuary. Estuar Coast Mar Sci 1: $107-111$

Kalle K (1966) The problem of gelbstoff in the sea. Oceanogr Mar Biol Annu Rev 4:91-104

Kenworthy WJ, Zieman JC. Thayer GW (1982) Evidence for the influence on the benthic nitrogen cycle in a coastal plain estuary near Beaufort, North Carolina (USA). Oecologia 54:152-158

Kingzett BC, Bourne N, Leask KL (1990) Induction of metamorphosis of the Japanese scallop Patinopecten yessoensis Jay. J Shellfish Res 9:119-124

Lipcius RN, Olmi EJ IlI, van Montfrans J (1990) Planktonic availability, molt stage and settlement of blue crab postlarvae. Mar Ecol Prog Ser 68:235-242

Litaker W, Duke CS, Kenny BE, Ramus J (1993) Short-term environmental variability and phytoplankton abundance in a shallow tidal estuary. II. Spring and fall. Mar Ecol Prog Ser 94:141-154

Little KT, Epifanio CE (1991) Mechanism for the reinvasion of the estuary by two species of brachyuran megalopae. Mar Ecol Prog Ser 68:235-242

McConaugha JR, Johnson DF, Provenzano AJ, Maris RC (1983) Seasonal distribution of larvae of Callinectes sapidus (Crustacea: Decapoda) in the waters adjacent to 
Chesapeake Bay. J Crustac Biol 3:582-591

Mense DJ, Wenner EL (1989) Distribution and abundance of early life history stages of the blue crab Callinectes sapidus in tidal marsh creeks near Charleston. South Carolina. Estuaries 12:157-168

Moran MA, Hodson RE (1994) Dissolved humic substances of vascular plant origin in a coastal marine environment. Limnol Oceanogr 39:762-771

Nissenbaum A, Kaplan IR (1972) Chemical and isotopic evidence for the in situ origin of marine humic substances Limnol Oceanogr 17:570-582

Noureddin S, Courtot P (1989) Conservative behavior of humic substances in a macrotidal estuary: composition of particulate and dissolved phase. Oceanologica Acta 12:381-391.

Olmi E.J III (1994) Vertical migration of blue crab Callinectes sapidus megalopae: implications for transport in estuaries. Mar Ecol Prog Ser 113:39-54

Olmi EJ III, van Montfrans J, Lipcius RN, Orth RJ, Sadler PW (1990) Variation in planktonic availability and settlement of blue crab megalopae in the York River, Virginia. Bull Mar Sci 46:230-243

Orth RJ, van Montfrans J (1987) Utilization of a seagrass meadow and tidal marsh creek by blue crabs Callinectes sapidus: I. Seasonal and annual variations in abundance with emphasis on post-settlement juveniles. Mar Ecol Prog Ser 41:283-294

Sandifer PA (1975) The role of pelagic larvae in recruitment to populations of adult decapod crustaceans in York River Estuary and adjacent lower Chesapeake Bay, Virginia. Estuar Coast Mar Sci 3:269-279

Editorial responsibility: Otto Kinne,

Oldendorf/Luhe, Germany
Schnitzer M, Khan SU (1972) Humic substances in the environment. Marcel. Dekker, Inc, New York

Sieburth JMCN, Jensen A (1968) Studies of algal substances in the sea. 1. Gelbstoff (humic material) in terrestrial and marine waters. J Exp Mar Biol Ecol 2:174-1.89

Sorensen PW (1986) Origin of freshwater attractant(s) of migrating elvers of the American eel, Anguilla rostrata Environ Biol Fish 17:185-200

Stevenson FJ, Butler JHA (1969) Chemistry of humic acids and related pigments. In: Eglinton G, Murphy MTJ (eds) Organic geochemistry. Springer-Verlag. New York, p $534-557$

Stevenson JR (1985) Dynamics of the integument. In: Bliss DE (ed) The biology of Crustacea, Vol 9, Integument, pigments, and hormonal processes. Academic Press, New York, p . 1-42

Stuermer DH, Harvey GR (1974) Humic substances from seawater. Nature 250:480-481

Tosi L, Sola C (1993) Role of geosmin, a typical inland water odour, in guiding glass eel Anguilla anguilla (L.) migration. Ethology 95:177-185

Wolcott DL, DeVries MC (1994) Offshore megalopae of Callinectes sapidus: depth of collection, molt stage and response to estuarine cues. Mar Ecol Prog Ser 109: $157-163$

Zar JH (1996) Biostatistical analysis. Prentice Hall, Inc, Englewood Cliffs, NJ

Zimmer-Faust, RK, Tamburn MN (1994) Chemical identity and ecological implications of a waterborne larval settlement cue. Limnol Oceanogr 39:1075-1087

Submitted: March 21, 1997; Accepted: June 30, 1997

Proofs received from author(s): September 10, 1997 